\title{
Establishing a Cartographic Body of Knowledge
}

\author{
Terje Midtb $\varnothing^{\mathrm{a}, *}$, Temenoujka Bandrova ${ }^{\mathrm{b}}$, Georg Gartner ${ }^{\mathrm{c}}$, Miljenko Lapaine ${ }^{\mathrm{d}}$, Jie Shen ${ }^{\mathrm{e}}$, Vit \\ Voženílek ${ }^{\mathrm{f}}$, Tao Wang $\mathrm{g}$ \\ ${ }^{a}$ Geomatics group, Dept. of Civil and Environmental Engineering, Norwegian University of Science and Technology, Trondheim, \\ Norway-terjem@ntnu.no \\ ${ }^{b}$ University of Architecture, Civil Engineering and Geodesy, Sofia - tbandrova@abv.bg \\ ${ }^{c}$ Technische Universität Wien, Department of Geodesy and Geoinformation-georg.gartner@tuwien.ac.at \\ ${ }^{d}$ University of Zagreb, Faculty of Geodesy - mlapaine@ geof.hr \\ ${ }^{e}$ Key Laboratory of Virtual Geographic Environment (Nanjing Normal University), Ministry of Education, Nanjing, Jiangsu 210023, \\ China-562972712@qq.com \\ ${ }^{f}$ Palacký University, Faculty of Science, Department of Geoinformatics, Olomouc, Czech Republic - vit.vozenilek@ upol.cz \\ ${ }^{g}$ Geographic Information Science, Capital Normal University - wangt@cnu.edu.cn \\ * Corresponding author
}

Keywords: Body of knowledge, Cartography, Cartographic tools, BoK

\begin{abstract}
:
During the past 10 years, the creation of a Cartographic Body of Knowledge (CartoBoK) has been a recurring issue in ICA. In 2006 the University Consortium for Geographic information Science introduced their GIS\&T Body of Knowledge. The collection has later been prepared for the Web environment, and the version of today is from 2016 (GIS\&T BoK, 2016). This BoK also includes a section on Cartography and Visualization. The section has however been considered as "not complete" when it comes to Cartography. As Chair of the ICA Commission for Education and Learning, David Fairbairn engaged in the BoK for Cartography work (Fairbairn, 2018). In parallel, the Executive Committee at ICA established a BoK Working Group in the period 2015-2019. This WG was chaired by Lynn Usery and co-chaired by Georg Gartner. Based on an evaluation of existing BoKs in neighbouring domains a comprehensive concept was developed, consisting of a starting list of terms, a strategy to involve the community through ICA Commissions, ICA conference participants and ultimately the crowd, and a concept to maintain the BoK by including consequently standardized meta data and allow for linked data relations to update entries. However, their work did not end up in a common agreement on a Cartographic BoK at the ICC in Tokyo 2019. In 2019, Harold Moellering (Moellering, 2019) did also look into the background for developing CartoBoK, in particular from the Analytical Cartography viewpoint.
\end{abstract}

Since the status for CartoBoK was "mission not completed" in 2019, the current President of ICA wanted a new focus on the establishment of the Body of Knowledge. Accordingly, he formed a new Working Group based on three members of the current Executive Committee. Later this group has been extended, and the current members are the authors of this paper.

Since the autumn 2020 this group has, through regularly online meetings, engaged in the CartoBoK work. At the ICA Generally Assembly in Tokyo, 2019, a review and renewal of existing, central definitions within Cartography was requested. In particular the definition of "a map". This task was assigned to the CartoBoK WG. A separate paper dealing with the suggested definitions is proposed for ICC in Florence (Lapaine et al., In review).

Another important issue is to establish how to structure the BoK. The WG concluded that "the map" is the most central element, and that other elements within Cartography are somehow connected to the map. We have basic Cartographic elements that are common for most Cartographic work (for example map projections), while other elements are unique for special fields of Cartography.

With a view to establish the CartoBok, the WG have studied BoKs for several other sciences. This includes Business Analysis (BABOK, 2015), Surveying (Bethel, 2011; Greenfeld, 2011a; Greenfeld, 2011b; Greenfeld, 2011c; Lathorp, 2011a; Lathorp, 2011b; Paiva, 2011) and Art (Wang, 2000; Stanley,2006 ; Wu, 2020). GIS\&T BoK (2016) is of course in particular interesting, since it includes Cartography and Visualization as a subset. GIS\&T BoK (2016) is also included as a part of the EO4GEO group (Earth Observation for Geoinformation) (EO4GEO BoK, 2018). The EO4GEO group uses "Living Textbook" (Living Textbook, 2021) and a "BoK Visualization and Search tool (BoK Visualization and Search, 2021) "for acquisition and presentation of the BoK. These tools are very intriguing, and 
similar approaches are considered for the CartoBoK. During the study of other BoKs, the WG concluded that the CartoBoK need to be a dynamic and maintained on a digital platform. It should not be a static document which can be cumbersome to update. It will be natural to use a kind of Web-based platform.

The different ICA commissions will play an important role when it comes to the content of CartoBoK. Many Cartographic elements are of common interest for several Commissions, while each of them also can have more specialized contributions for the BoK.

As mentioned earlier, CartoBoK needs to be dynamic. Even if much of the content will exist for a long time, new technology and new methods will demand a system for continuous updating and renewal of the BoK. This should be handled by ICA. Maybe we need a permanent Working Group allocated to this task?

It is our intention to present the ongoing work in the CartoBoK Working Group at ICC in Florence, to get inputs and acceptance from the Cartographic community for our further work.

\section{References}

BABOK (2015). Guide to Business Analysis Body of Knowledge: IIBY : 9781927584026 (3rd ed.). (2015). International Institute of Business Analysis. ISBN: 978-1-927584-03-3

Bethel, J. (2011): Imaging Body of Knowledge for the Professional Surveyor, Surveying and Land Information Science, Vol. 71, Nos. 3\&4, 147-156

BoK - eo4geo. (2018). Earth Observation for geoinformation. http://www.eo4geo.eu/bok/ (Accessed 27-05-2021)

BoK Visualization and search. (2021). http://bok.eo4geo.eu/ (Accessed 01-06-2021)

Fairbairn, D. (2018). Creating a Body of Knowledge for cartography. Proceedings of the ICA, 1, 1-5. https://doi.org/10.5194/ica-proc-1-35-2018

GIS\&T BoK (2016). GIS\&T Body of Knowledge. https://gistbok.ucgis.org/ (Accessed 28-05-2021)

Greenfeld, J. (2011a): Foreward: Surveying Body of Knowledge, Surveying and Land Information Science, Vol. 71, Nos. 3\&4, 103-104

Greenfeld, J. (2011b): Surveying Body of Knowledge, Surveying and Land Information Science, Vol. 71, Nos. 3\&4, 105-113

Greenfeld, J. (2011c): GIS Body of Knowledge for Surveying, Surveying and Land Information Science, Vol. 71, Nos. $3 \& 4,115-133$

Lapaine, M., Midtbø, T., Gartner, G., Bandrova, T., Wang, T., \& Shen, J. (2021)(In review). Definition of the map. International Cartographic Conference, Florence.

Lathrop, W., Lucas, J. N. (2011a): Surveying's Legal Body of Knowledge, Surveying and Land Information Science, Vol. 71, Nos. 3\&4, 157-171

Lathrop, W. (2011b): Surveying Body of Knowledge-Land Stewardship, Surveying and Land Information Science, Vol. 71, Nos. 3\&4, 173-182

Living Textbook (2021). Universiteit Twente. https://www.itc.nl/about-itc/organization/resources-facilities/livingtextbook/ (Accessed 01-06-2021)

Moellering, H. (2019). Analytical Background for Developing a Body of Knowledge for Cartography. Proceedings of the ICA, 2, 1-4. https://doi.org/10.5194/ica-proc-2-87-2019

Paiva, J. (2011): Surveying Body of Knowledge for Positioning, Surveying and Land Information Science, Vol. 71, Nos. 3\&4, 135-145

Stanley Jr, W., \& Mayer, J. W. (2006). The science of paintings. Springer Science \& Business Media.

Wang, H.J. (2000). Introduction to Art. Beijing:Culture and Art Publishing House.

Wu, H., Liu, S. Y., Zheng, W., Yang, Y., \& Gao, H. (2020). PaintKG: the painting knowledge graph using bilstm-crf. 2020 International Conference on Information Science and Education (ICISE-IE) (pp. 412-417). IEEE. https://ieeexplore.ieee.org/abstract/document/9418951 (Accessed 02-06-2021) 